\title{
The Diagnostic Accuracy of Combined Colposcopy, Cytology, and Target Biopsy of Carcinoma in Situ of the Uterine Cervix
}

\author{
Akira Yajtma, Masaaki Watanabe, Toshihiko Mori and \\ YUKINORI YONEMOTO \\ Department of Obstetrics and Gynecology, Tohoku University \\ School of Medicine, Sendai 980
}

Yajma, A., Watanabe, M., Mori, T. and Yonemoto, Y. The Diagnostic Accuracy of Combined Colposcopy, Cytology, and Target Biopsy of Carcinoma in Situ of the Uterine Cervix. Tohoku J. exp. Med., 1978, 126 (2), 185-192 — The results of cytology, colposcopy and target biopsy in 91 cases diagnosed by conization as uterine cervical carcinoma in situ and 39 cases diagnosed as microinvasive carcinoma were compared. Lesions limited to the ectocervix could be identified by colposcopy, and those identified as carcinoma in situ by cytology or target biopsy were all included in the group diagnosed as carcinoma in situ by conization. Among the 29 cases of carcinoma in situ limited to the ectocervix, 19 $(66 \%)$ were similarly diagnosed by both cytology and target biopsy, allowing for us to avoid conization. For cases diagnosed as microinvasive carcinoma using target biopsy, conization must also be performed in order to determine the depth of invasion. Even in cases diagnosed as dysplasia or careinoma in situ by target biopsy, when it is thought that the lesion may extend into the cervical canal or in cases where agreement with the eytological results is not found, conization is necessary. - colposcopy; cytology of the uterine cervix; target biopsy; conization; preclinical carcinoma of the cervix

Thanks to the systematic population screening for uterine cervical cancer, the opportunities for discovering malignant lesions in an early stage have greatly increased. Since many patients with early malignant changes are young, there is a tendency to perform individualized treatment and reduce the complications which accompany radical hysterectomy in early cervical neoplasms. Therefore, it is extremely important to make a reliable diagnosis prior to definitive surgery on malignant lesions of the uterine cervix. For this purpose conization is the most effective method, but because of the danger of hemorrhage following conization, it cannot be used for outpatients. Consequently, conization with hospitalization has been performed, but since this imposes expensive hospital charges on the patient and there are intricate problems in performing two surgical procedures, it would be beneficial for both patient and doctor alike if the conization procedure could be avoided. This paper reports the results of three outpatient diagnostic methods, colposcopy, cytology and target biopsy, used preoperatively in cases ultimately diagnosed as having carcinoma in situ.

Received for publication, March 10, 1978. 


\section{Materials and Methods}

The results of diagnosis by colposcopy, cytology and target biopsy in 91 patients diagnosed by conization using an 8 block serial section of the cervix as having carcinoma in situ and 39 patients diagnosed as having microinvasive carcinoma were compared with regard to the location of the lesions. Colposcopy was performed by applying $3 \%$ acetic acid solution to the portio vaginalis and the cervical canal after taking off the cervical mucus, and any abnormal colposcopical findings were then recorded. Cytology entailed performing Papanicolaou staining after scraping the portio and cervical canal with a wooden spatula, carcinoma in situ and microinvasive carcinoma could then be determined cytologically. Target biopsy entailed colposcopic investigation for abnormalities, obtaining two or three tissue samples and performing HE staining. Definitive therapy consisted of abdominal or vaginal simple hysterectomy for cases of carcinoma in situ and extended hysterectomy for cases of microinvasive carcinoma. Diagnostic criteria for carcinoma in situ were as follows: (a) lateral invasion or mesenchymolysis, (b) lots of abnormal mitosis, or (c) lack of differentiation, replacement of the whole epithelial layer with cells having lost their polarity, in cases where abnormal epithelium of the uterine cervix does not exceed the basement membrane (Noda et al. 1976). A depth of invasion into the stroma measured from the shallowest basement membrane directly above the area of the invasion was diagnostic for microinvasive carcinoma when it was less than $3 \mathrm{~mm}$. Cases with a depth of invasion less than $3 \mathrm{~mm}$ but with a pattern of invasion indicating confluent invasion or vessel permeation were included among the group with microinvasive carcinoma.

\section{Results}

The location of the cervical lesion diagnosed with conization as carcinoma in situ or microinvasive carcinoma is classified as shown in Table 1 with respect to the external os of the uterus. Cases of lesions only external to the external os of the uterus, in other words, lesions of the ectocervix were designated as A-type; lesions located both internal and external to the external os of the uterus were designated as B-type; and lesions only internal to the external os, limited to the endocervix, designated as C-type. B-type lesions of both carcinoma in situ and microinvasive carcinoma were the commonest, followed by A-type lesions of carcinoma in situ and $\mathrm{C}$-type lesions of microinvasive carcinoma. The average age of the patients was 38.4 years, 44.4 years and 48.9 years for the A-, B-, and C-type lesions, respectively (Table 1 ).

TABLE 1. Location of lesions diagnosed as carcinoma in situ or microinvasive carcinoma by conization relative to the external os of the uterus

\begin{tabular}{cccc}
\hline & \multirow{2}{*}{$\begin{array}{c}\text { External os of } \\
\text { the uterus }\end{array}$} & \multicolumn{2}{c}{ Number of cases } \\
\cline { 3 - 4 } & & 29 & $\begin{array}{c}\text { Microinvasive } \\
\text { carcinoma }\end{array}$ \\
\hline B & & 44 & 2 \\
C & 18 & 27 \\
& Total & 91 & 10 \\
\hline
\end{tabular}


A variety of residual diseases in samples from hysterectomies performed subsequently to conization are shown in Tables 2 and 3 . One A-type case, shown in Table 2, had residual carcinoma in situ which was located in the vaginal wall. Two B-type cases had dysplasia remaining deep within the cervical canal. Among the 91 cases of carcinoma in situ diagnosed with conization $88(97 \%)$ showed no residual diseases in hysterectomy samples. In contrast, among the cases diagnosed by conization as microinvasive carcinoma, hysterectomy samples showed dysplasia remaining in 6 cases, carcinoma in situ remaining in 1 case and microinvasive carcinoma remaining in 7 cases; all of these were located within the cervical canal. In other words, 25 of these 39 patients $(64 \%)$ showed no residual diseases at hysterectomy.

TABLE 2. Types of residual diseases found in hysterectomy samples in cases diagnosed as carcinoma in situ

\begin{tabular}{cccc}
\hline & \multicolumn{3}{c}{ Residual diseases } \\
\cline { 2 - 4 } Type of location & Dysplasia & Carcinoma in situ & No disease \\
\hline A & 0 & 1 & 28 \\
B & 2 & 0 & 42 \\
C & 0 & 0 & 18 \\
Total & 2 & 1 & 88 \\
\hline
\end{tabular}

TABLE 3. Types of residual diseases found in hysterectomy samples in cases diagnosed as microinvasive carcinoma by conization

\begin{tabular}{ccccc}
\hline & \multicolumn{4}{c}{ Residual diseases } \\
\cline { 2 - 5 } Type of location & Dysplasia & Carcinoma in situ & $\begin{array}{c}\text { Microinvasive } \\
\text { carcinoma }\end{array}$ & No disease \\
\hline A & 0 & 0 & 0 & 2 \\
B & 4 & 1 & 5 & 17 \\
C & 2 & 0 & 2 & 6 \\
Total & 6 & 1 & 7 & 25 \\
\hline
\end{tabular}

The relationship between abnormal colposcopic findings and the location of the lesions is expressed in Table 4. In cases of carcinoma in situ or microinvasive carcinoma located in the ectocervix (Types $A$ and $B$ ), the rate of abnormal colposcopic findings was high, approximately $90 \%$. In contrast, C-type cases, where the lesion was limited to the endocervix, showed a relatively low rate of abnormal colposcopic findings.

A comparison of diagnoses based upon cytology with those based upon histological examination following conization are shown in Table 5 . With regard to carcinoma in situ accurate cytological diagnoses were possible in 22 out of 29 A-type cases $(76 \%), 30$ out of 44 B-type cases $(68 \%$ ) and 7 out of $18 \mathrm{C}$-type cases $(39 \%)$. However, the results of cytology in patients having carcinoma in situ and 
microinvasive carcinoma were found to be only suspicious of malignancy in 26 of the 130 cases $(20 \%)$.

A comparison of diagnoses by target biopsy and conization is shown in Table 6. With regard to carcinoma in situ, agreement in the diagnosis was obtained in

TABLE 4. The relationship among abnormal colposcopic findings, type of lesion and location

\begin{tabular}{|c|c|c|c|c|}
\hline \multirow{2}{*}{ Type of location } & \multirow{2}{*}{ Diagnosis by conization } & \multicolumn{2}{|c|}{ Colposcopic findings } & \multirow{2}{*}{ Total } \\
\hline & & Abnormal & Normal & \\
\hline \multirow{2}{*}{ A } & Carcinoma in situ & 25 & 4 & 29 \\
\hline & Microinvasive carcinoma & 2 & 0 & 2 \\
\hline \multirow{2}{*}{ B } & Carcinoma in situ & 39 & 5 & $4 \overrightarrow{4}$ \\
\hline & Microinvasive carcinoma & 25 & 2 & 27 \\
\hline \multirow{2}{*}{$\mathrm{C}$} & Carcinoma in situ & 8 & 10 & 18 \\
\hline & Mieroinvasive carcinoma & 8 & 2 & 10 \\
\hline Total & & 107 & 23 & 130 \\
\hline
\end{tabular}

TaBle 5. A comparison of diagnosis by conization and diagnosis by cytology

\begin{tabular}{|c|c|c|c|c|c|}
\hline \multirow{2}{*}{$\begin{array}{l}\text { Type of } \\
\text { location }\end{array}$} & \multirow[b]{2}{*}{ Diagnosis by conization } & \multicolumn{3}{|c|}{ Diagnosis by cytology } & \multirow{2}{*}{ Total } \\
\hline & & Suspicious & $\begin{array}{l}\text { Carcinoma } \\
\text { in situ }\end{array}$ & $\begin{array}{c}\text { Microinvasive } \\
\text { carcinama }\end{array}$ & \\
\hline \multirow{2}{*}{ A } & Carcinoma in situ & 5 & 22 & 2 & 29 \\
\hline & Microinvasive carcinoma & 0 & 0 & 2 & 2 \\
\hline \multirow{2}{*}{$\mathrm{B}$} & Carcinoma in situ & 9 & 30 & 5 & 44 \\
\hline & Microinvasive carcinoma & 2 & 12 & 13 & 27 \\
\hline \multirow{2}{*}{$\mathrm{C}$} & Carcinoma in situ & 9 & 7 & 2 & 18 \\
\hline & Microinvasive carcinoma & 1 & 4 & 5 & 10 \\
\hline Total & & 26 & 75 & 29 & 130 \\
\hline
\end{tabular}

TaBle 6. A comparison of diagnosis by conization and diagnosis by target biopsy

\begin{tabular}{|c|c|c|c|c|c|}
\hline \multirow{2}{*}{$\begin{array}{l}\text { Type of } \\
\text { location }\end{array}$} & \multirow[b]{2}{*}{ Diagnosis by conization } & \multicolumn{3}{|c|}{ Diagnosis by target biopsy } & \multirow[b]{2}{*}{ Total } \\
\hline & & Dysplasia & $\begin{array}{l}\text { Carcinoma } \\
\text { in situ }\end{array}$ & $\begin{array}{c}\text { Microinvasive } \\
\text { carcinoma }\end{array}$ & \\
\hline \multirow{2}{*}{ A } & Carcinoma in situ & 1 & 27 & 1 & 29 \\
\hline & Microinvasive carcinoma & 0 & 1 & 1 & 2 \\
\hline \multirow{2}{*}{$\mathrm{B}$} & Carcinoma in situ & 2 & 39 & 3 & 44 \\
\hline & Microinvasive carcinoma & 0 & 22 & 5 & 27 \\
\hline \multirow{2}{*}{$\mathrm{C}$} & Carcinoma in situ & 1 & 14 & 3 & 18 \\
\hline & Microinvasive carcinoma & 0 & 5 & 5 & 10 \\
\hline Total & & 4 & 108 & 18 & 130 \\
\hline
\end{tabular}

27 out of 29 A-type cases (93\%), 39 out of 44 B-type cases (89\%) and 14 out of 19 C-type cases $(78 \%)$. With regard to microinvasive carcinoma, the diagnosis was in agreement in the A-, B-, and C-type cases in 1, 5, and 5 cases each.

The presence or absence of abnormal colposcopic findings, the results of 
cytology and target biopsy in comparison with diagnosis by conization in all the patients are compared in Tables 7, 8, and 9 according to the location of the lesion. From these tables, it is apparent that underdiagnosis using cytology and target biopsy relative to conization occurred in 1 out of 31 A-type cases (Table 7), 13 out of 71 B-type cases (Table 8) and 5 out of 28 C-type cases (Table 9). In 9 out of the 13 underdiagnosed B-type lesions, the lesion could be viewed only partially using the colposcope, and in any of the 5 underdiagnosed C-type lesions, the entire lesion could not be seen.

TABLE 7. A comparison of the results of conization, target biopsy, cytology and colposcopic findings in lesions limited to the ectocervix (A-type)

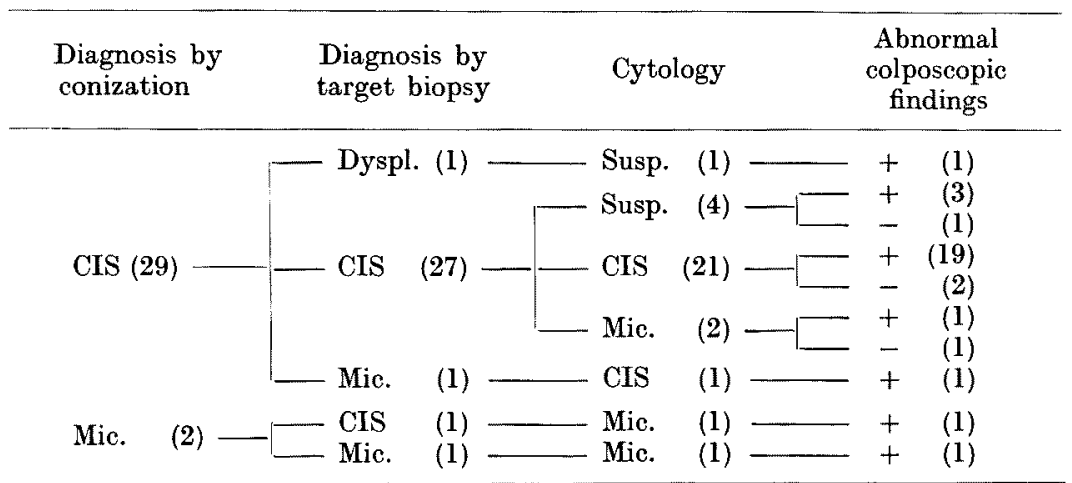

( ), number of cases; CIS, carcinoma in situ; Dyspl., dysplasia; Mic., microinvasive carcinoma; Susp., suspicious.

TABLE 8. A comparison of the results of conization, target biopsy, cytology and colposcopic findings in lesions extending into the cervical canal (B-type)

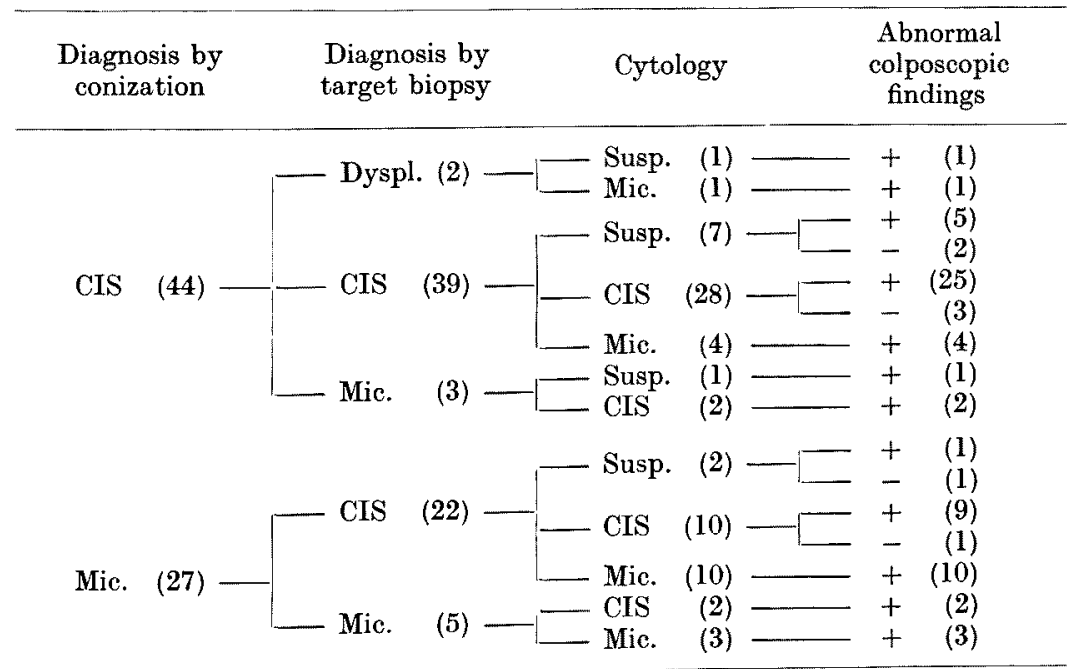

Abbreviations are the same as in Table 7. ( ), number of cases. 
TABLE 9. A comparison of the results of conization, target biopsy, cytology and colposcopic findings in lesions limited to the endocervix (C-type)

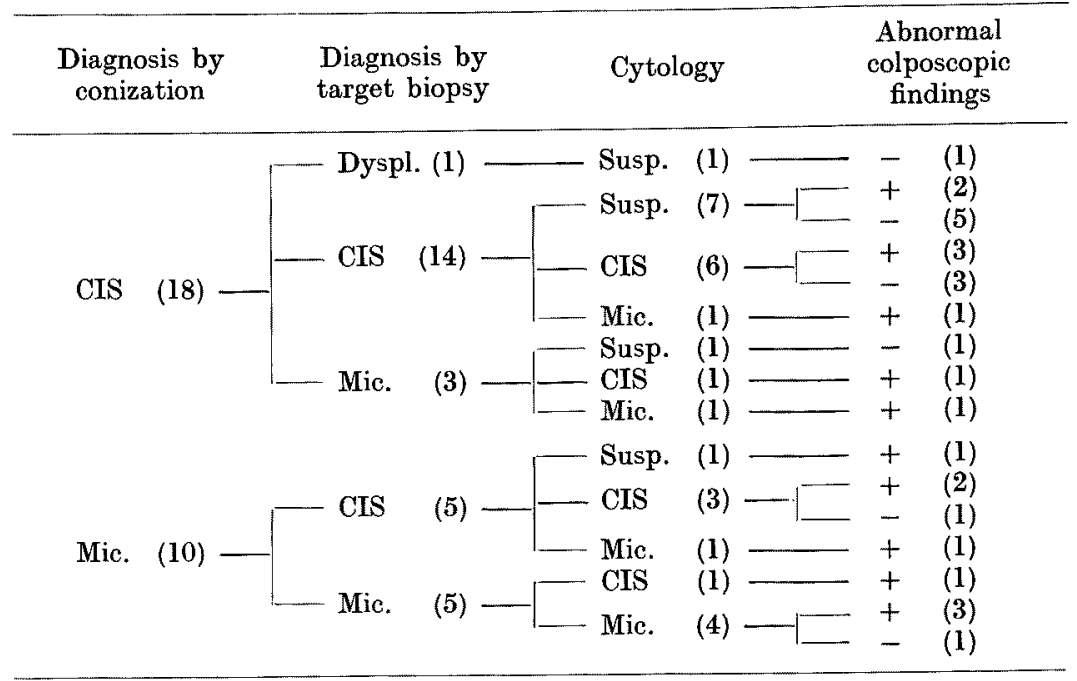

Abbreviations are the same as in Table 7. ( ), number of cases.

\section{Discussion}

Originally, colposcopy and cytology were used as supplemental diagnostic techniques in diagnosing cervical malignant tumors. Consequently, it has been accepted to use cytology to verify the presence of malignant changes and to use colposcopy to find its location. Nonetheless, due to the recent progress in cytological diagnostic techniques, it has become possible to make a high proportion of accurate histological diagnoses using cytology alone. The rate of false negative diagnosis of carcinoma in situ or microinvasive carcinoma based upon cervical scrapings with a wooden spatula does not exceed 1 or $2 \%$ (Yajima et al. 1972). In other words, nearly all of these lesions can be detected by cytology. However, the agreement between histological and cytological diagnoses remains at the 46 to $80 \%$ level (Chao et al. 1969). In cases where lesions are located on the ectocervix, the rate of agreement between cytological and histological diagnoses is higher, as seen in Table 5 .

In cases of carcinoma in situ or microinvasive carcinoma, the rate of abnormal colposcopical findings reaches 80 to $97 \%$ (Limburg 1958; Navratil et al. 1958; Donohue and Meriwether 1972; Stafl and Mattingly 1973; Hovadhanakul et al. 1976; Nishimura 1976), but the rate of being able to see the entire lesion is commonly low, here being 56\% and 66\% (Hollyock and Chanen 1972; Chanen and Hollyock 1974). The primary cause for this is that the lesion extends into the cervical canal or is limited to the endocervix.

The agreement between diagnosis by punch biopsy and conization or diagnosis based upon samples of hysterectomy is, as indicated by many authors, higher in target biopsy with colposcopy than in punch biopsy without colposcopy (Ortiz et al. 
1969; Scott et al. 1969; Townsend et al. 1970; Donohue and Meriwether 1972; Krumholz and Knapp 1972; Selim et al. 1973; Boelter and Newman 1975). Yet, it is necessary that the number of tissue samples taken by the punch is adequate (Gusberg and Marshall 1962; Griffiths et al. 1964; Holley 1971). However, no matter how many tissue samples are taken, in cases where the entire lesion cannot be seen with the colposcope, punch biopsy cannot be the final diagnostic method. This is because the possibility of more advanced lesions other than those obtained by punch biopsy (especially the many remaining deep within the cervical canal) cannot be ruled out (Moore et al. 1961; Beller and Khatamee 1966; Silber and Woodruff 1966; Anderson and Linton 1967; Crapanzano 1972) In the present study, it was found that diagnosis with punch biopsy resulted in underdiagnosis in cases of lesions extending into the cervical canal compared with the results of conization in 24 of 71 B-type cases and 6 of 28 C-type cases. Among these, the results of both cytology and punch biopsy differed from those of conization in 13 and 5 cases, respectively. As indicated by Stafl and Mattingly (1973), it is extremely difficult if one is not an experienced colposcopist to determine the extent of the lesion when it extends into or is limited to the cervical canal. Consequently, conization should be performed in cases where the entire lesion cannot be viewed with the colposcope, in cases where cytology is positive for malignancy but abnormal colposcopic findings are not obtained, and in cases where cytology indicates microinvasion (Christopherson et al. 1967). Of course, it goes without saying that conization should be performed in cases where punch biopsy indicates microinvasive carcinoma in order to determine the depth of invasion.

Lesions of the ectocervix (which all gynecologists can safely diagnose by finding colposcopic ectopy of the entire area outside the external os of the uterus) which are identified as carcinoma in situ by cytology and target biopsy were all diagnosed as carcinoma in situ by conization, as shown in Table 7. Consequently, for these cases conization can be safely avoided and the definitive treatment of carcinoma in situ can be performed (Tovell et al. 1976). As mentioned above, conization could be ultimately avoided in 19 of the 29 cases $(66 \%)$ with lesions limited to the ectocervix. In at least 19 of the 91 carcinoma in situ cases $(21 \%)$ (questions concerning the location of the lesion aside) or, in roughly $20 \%$ of the carcinoma in situ cases coinization can be avoided and accurate diagnosis obtained using only cytology and target biopsy.

\section{References}

1) Anderson, S.G. \& Linton, E.B. (1967) The diagnostic accuracy of cervical biopsy and cervical conization. Amer. J. Obstet. Gynec., 99, 113-116.

2) Beller, F.K. \& Khatamee, M. (1966) Evaluation of punch biopsy of the cervix under direct colposcopic observation (target punch biopsy). Obstet. Gynec., 28, 622-625.

3) Boelter, W.C. \& Newman, R.L. (1975) The correlation between colposcopic grading, directed punch biopsy, and conization. Amer. J. Obstet. Gynec., 122, 945-946.

4) Chanen, W. \& Hollyock, V.E. (1974) Colposcopy and the conservative management of cervical dysplasia and carcinoma in situ. Obstet. Gynec., 43, 527-534.

5) Chao, S., McCaffrey, R.M., Todd, W.D. \& Moore, J.G. (1969) Conization in evaluation 
and management of cervical neoplasia. Amer. J. Obstet. Gynec., 103, 574-584.

6) Christopherson, W.M., Gray, L.A. \& Parker, J.E. (1967) Role of punch biopsy in subclinical lesions of the uterine cervix. Obstet. Gynec., 30, 806-811.

7) Crapanzano, J.T. (1972) Office diagnosis in patients with abnormal cervicovaginal cytosmears: Correlation of colposcopic biopsy and cytologic findings. Amer. J. Obstet. Gynec., 113, 967-972.

8) Donohue, L.R. \& Meriwether, W. (1972) Colposcopy as a diagnostic tool in the investigation of cervical neoplasias. Amer. J. Obstet. Gynec., 113, 107-110.

9) Griffiths, C.T., Austin, J.H. \& Younge, P.A. (1964) Punch biopsy of the cervix. Amer. J. Obstet. Gynec., 88, 695-703.

10) Gusberg, S.B. \& Marshall, D. (1962) Intraepithelial carcinoma of the cervix: A clinical reappraisal. Obstet. Gynec., 19, 713-720.

11) Holley, M.R. (1971) Management of the patient with an abnormal Papanicolaou smear. Amer. J. Obstet. Gynec., 110, 979-983.

12) Hollyock, V.E. \& Chanen, W. (1972) The use of the colposcope in the selection of patients for cervical cone biopsy. Amer. J. Obstet. Gynec., 114, 185-189.

13) Hovadhanakul, P., Mehra, U., Terragno, A., Taylor, H.B. \& Cavanagh, D. (1976) Comparison of colposcopy directed biopsies and cold knife conization in patients with abnormal cytology. Surg. Gynec. Obstet., 142, 333-336.

14) Krumholz, B.A. \& Knapp, R.C. (1972) Colposcopic selection of biopsy sites. Obstet. Gynec., 39, 22-26.

15) Limburg, H. (1958) Comparison between cytology and colposcopy in the diagnosis of early cervical carcinoma. Amer. J. Obstet. Gynec., 75, 1298-1301.

16) Moore, J.G., Morton, D.G., Applegate, J.W. \& Hindle, W. (1961) Management of early carcinoma. Amer. J. Obstet. Gynec., 81, 1175-1182.

17) Navratil, E., Burghardt, E., Bajardi, F., Austria, G. \& Nash, W. (1958) Simultaneous colposcopy and cytology used in screening for carcinoma of the cervix. Amer. J. Obstet. Gynec., 75, 1292-1297.

18) Nishimura, A., Sugimori, H., Tsukamoto, N., Kashimura, M. \& Taki, I. (1976) Discrepancy between diagnosis by cytology and directed punch biopsy and final diagnoses in cervical borderline lesions. J. Jap. Soc. clin. Cytol., 15, 123-130. (Japanese)

19) Noda, K., Yajima, A., Higashiiwai, H., Sato, A. \& Teshima, K. (1976) Histopathologic criterion of dysplasia of the uterine cervix and its biological nature. Acta cytol., 20, 224-228.

20) Ortiz, R., Newton, M. \& Langlois, P.L. (1969) Colposcopic biopsy in the dignosis of carcinoma of the cervix. Obstet. Gynec., 34, 303-306.

21) Scott, J.W., Brass, P. \& Seckinger, D. (1969) Colposcopy plus cytology. Results in 1,100 patients. Amer. J. Obstet. Gynec., 103, 925-929.

22) Selim, M.A., So-Bosita, J.L., Blair, O.M. \& Little, B.A. (1973) Cervical biopsy versus conization. Obstet. Gynec., 41, 177-182.

23) Silber, E.L. \& Woodruff, J.D. (1966) Evaluation of biopsy, cone, and hysterectomy sequence in intraepithelial carcinoma of the cervix. Obstet. Gynec., 27, 89-97.

24) Staf, A. \& Mattingly, R.F. (1973) Colposcopic diagnosis of cervical neoplasia. Obstet. Gynec., 41, 168-176.

25) Tovell, H.M.M., Banogan, P. \& Nash, A.D. (1976) Cytology and colposcopy in the diagnosis and management of preclinical carcinoma of the cervix uteri: A learning experience. Amer. J. Obstet. Gynec., 124, 924-934.

26) Townsend, D.E., Ostergard, D.R., Mishell, D.R. \& Hirose, F.M. (1970) Abnormal Papanicolaou smears. - Evaluation by colposcopy, biopsies, and endocervical curettage - Amer. J. Obstet. Gynec., 108, 429-434.

27) Yajima, A., Sato, S., Sato, A. \& Noda, K. (1972) Evaluation of cytology in detecting dysplasia of the uterine cervix. The World of Obstet. Gynec., 24, 665-672. (Japanese) 